\title{
A STUDY ON AETIOPATHOGENESIS AND MANAGEMENT OF NASAL POLYPOSIS
}

\author{
R Sowmya ${ }^{1}$, D Mahesh *2.
}

${ }^{1}$ Assistant Professor in Department of ENT, Dr. Patnam Mahendar reddy Institute of Medical Sciences, Chevella, Rangareddy, Telangana, India.

${ }^{* 2}$ Civil assistant surgeon specialist in ENT, Area hospital, Kamareddy, Telangana, India.

\section{ABSTRACT}

Nasal polyps are one of the most common inflammatory mass lesions of the nose. Their etiology remains unclear, but they are known to have associations with allergy, asthma, infection, fungus,cystic fibrosis, and aspirin sensitivity. However, the underlying mechanisms interlinking these pathologic conditions to nasal polyp formation remain unclear. In the present cross-sectional study was carried with 100 patients diagnosed with nasal polyposis in the age group of 10-60 years of both the sexes were studied during this period from June 2014 to October 2015 in the department of ENT, Kakatiya medical college attached to MGM Hospital, Warangal were found in large majority age groups of 11 - 30 years, men are most commonly seen affecting than women (men: women are 2:1).Allergic rhinitis is strongly associated with nasal polyposis, most common symptom is nasal obstruction, anosmia and facial pain are also seen.Most of the patients had nasal polyps reaching beyond the middle turbinate. And also, most of the patients had bilateral ethmoidalopacification on CT scan.only few showed sphenoid and frontal opacities.Steroid therapy was useful in $38 \%$ of patients.All others required endoscopic sinus surgery. Also, strong genetic factors are implicated in the pathogenesis of nasal polyps, but genetic and molecular alterations required for its development and progression are still unclear.

KEY WORDS: Allergic rhinitis,Anosmia, Facial pain, Nasal obstruction, Nasal polyposis, and Rhinorrhoea.

Address for correspondence: D Mahesh, Flat no. 403, Priya residency, Mythri nagar, Madinaguda, Hyderabd-500049, India.E-Mail: s.ramarappu@gmail.com; maheshdasari6@gmail.com

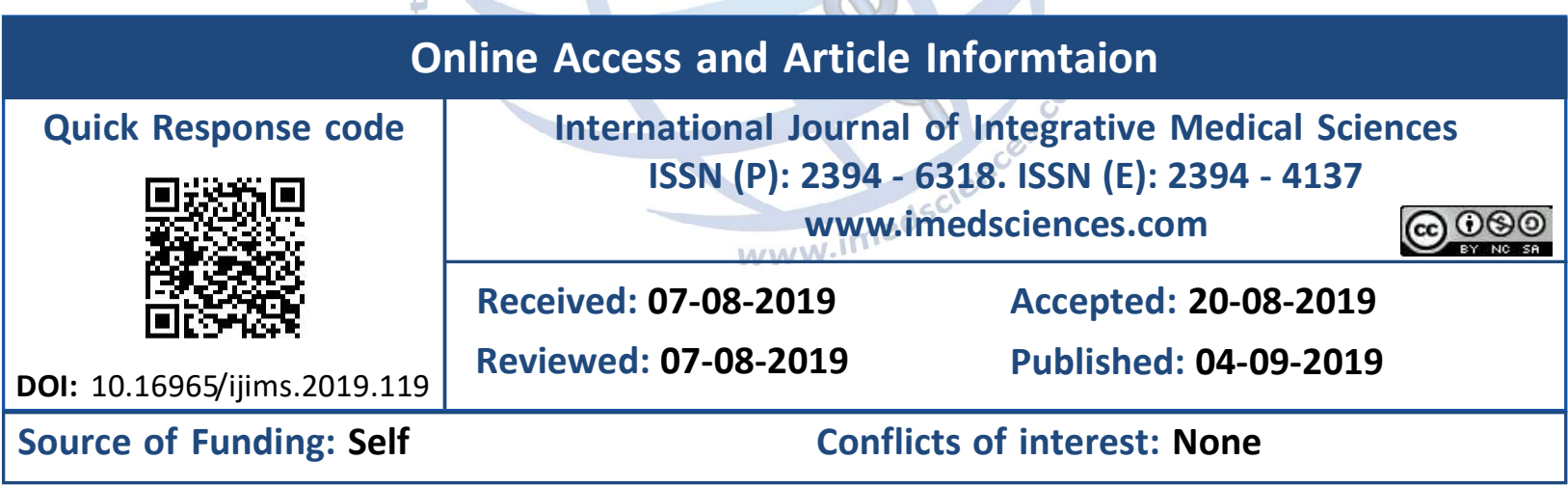

\section{INTRODUCTION}

Nasal polyposis is grey-white, painless, pendunculated mass of nasal mucosa. They are unique in their position and their composition, regarded as one form of chronic inflammation in the nose and sinuses, part of the spectrum of chronic rhino sinusitis. Nasal polyps have tendency to recur as long as the underlying disease is not eradicated. The prevalence rate is about 2 percent, increases with age reaching a peak in those aged 50 years and older [1].

On examination, polyps appear to be a uniform inflammatory reaction of nasal mucosa as "pale bags" which arise most commonly from middle meatus and the anterior ethmoidal cells, are relatively insensitive when probed. They commonly occur in systemic diseases such as immotile cilia syndrome, cystic fibrosis, aspirin intolerance and often coincide with intrinsic asthma. Patients with Nasal polyposis suffer from nasal obstuction, recurrent sinusitis, hyposmia, headache, post nasal drip and asthma with or without aspirin sensitivity [2]. Therapy of nasal polyps is one of the major challenges for both conservative and surgical approaches including endoscopic sinus surgery. The management of nasal polyposis has been the topic 
of frequent controversial debates for many decades. Most authors agree on the fact that the management of nasalpolyp should be primarily based on a medical approach, to be completed by surgical procedures only in the case of drug failure [3].

Treatment with oral or intranasal steroids has been shown to reduce polyp size, relieve symptoms, and reduce recurrence rates after surgery. Short courses of systemic steroids may also be used mainly in moderate to severe polyps to induce a rapid polyp size reduction, facilitating the ability of the intranasal steroids to gain access to the polypoid tissue [4]. Surgery is a straight forward option in patients with pansinus polyps, those not responding to medical management or has subsequent relapses [5]. It includes polypectomy and functional endoscopic sinus surgery (FESS) by Messerklinger traditional instrumentation technique [6-9]. The aim of this technique is to remove the pathologic tissues inside the osteomeatal complex units and to restore the corrupted mucociliary clearance and sinus ventilation without harming normal nasal physiology and anatomy [6].

After endoscope came in routine use for surgeries, the limitation of only one hand being available to do all other tasks was felt. A logical development from this reality was a need for a surgical instrument that could perform a variety of tasks at once. Powered sinus instruments entered the landscape several decades ago, with the introduction of the microdebrider [7]. Microdebrider provides satisfactory results by making dissection faster, almost bloodless and safe, and lets rapid healing of tissues without harming normal mucosa [8].

The understanding of pathophysiology and the management of nasal polyposis has long been a vexing problem for the treating clinician. The past two decades have seen a confluence of advances in optics, radiographic imaging and surgical technique. The emergence of nasal endoscopes and computed tomography have revolutionized our understanding and pathophysiology of nasal polyposis and have radically changed the concept of its management, effectiveness of various modalities of treatment.

\section{MATERIALS AND METHODS}

The Cross-sectional study was carried with 100 patients diagnosed with nasal polyposis in the age group of 10-60 years of both the sexes were studied during this period from June 2014 to October 2015 in the department of ENT, Kakatiya medical college attached toMGM Hospital, Warangal. Pregnant or lactating women, unable to tolerate surgery with general or local anesthesia due to concurrent medical conditions, past history of prior sinus surgery, patients presenting with unilateral nasal masses that mimic nasal polyps like encephalocele, angiofibroma, invertedpapilloma, nasolacrimalductcyst, haemangiomas, lymphomas, nasopharyngeal carcinoma, sarcoma, chordae, gliomas, neuroblastomas, dermoid tumors, and patients in whom steroids are contraindicated were excluded from the study. All the patients included in the study were questioned, a detailed history was elicited. Complete nasal examination was done including diagnostic nasal endoscopy. Mackay and Lund endoscopic staging system was used to grade the polyps with respect to middle meatus. Results were graded according to the extent of invasion of polyps. They were Stage 1 (extending to the middle meatus), stage 2 (extending to areas beyond the middle conchae without reaching the floor of the nasal passage) and stage 3 (extending through the entire nasal passage).

Table 1: Endoscopic scoring of nasal polyps.

\begin{tabular}{|c|c|}
\hline Endoscopic appearance & Score \\
\hline No polyps & 0 \\
\hline Restricted to middle meatus & 1 \\
\hline Below middle turbinate & 2 \\
\hline Massive polyposis & 3 \\
\hline
\end{tabular}

Table 2: Endoscopic scoring in each sinus.

\begin{tabular}{|c|c|c|}
\hline Sinus & Right & Left \\
\hline Maxillary & $0-2$ & $0-2$ \\
\hline Anterior ethmoid & $0-2$ & $0-2$ \\
\hline Posterior ethmoid & $0-2$ & $0-2$ \\
\hline Sphenoid & $0-2$ & $0-2$ \\
\hline Frontal & $0-2$ & $0-2$ \\
\hline Osteomeatal complex & $0 / 2$ & $0 / 2$ \\
\hline Total & $\mathbf{0 - 1 2}$ & $\mathbf{0 - 1 2}$ \\
\hline
\end{tabular}

Plain computerized tomography of the paranasal sinuses was done to know the extent of polyps 
and associated sinusitis. A scoring system was used to know the extent of polyposis in the CT scans.

\section{CT SCAN STAGING OF NASAL POLYPOSIS}

NO OPACITY - 0

\section{SOME OPACITY- 1}

TOTAL OPACITY - 2

TREATMENT: The treatment advised to the patients was either medical and/or surgical therapy.Thorough preoperative assessment of the patients was done.Medical management included topical steroids for period of one month and oral steroids for the period of 2 weeks. Follow up done for 3 weeks, 6 weeks and 3 months. Surgical treatment included Functional endoscopic sinus surgery. Post operatively patients were followed for first week, 3 weeks, and at 3 months.All patients following either medical or surgical therapy were examined for reduction of symptoms, decrease in the size of the polyp by nasal endoscopy and for crusting or synched formation.

OPERATIVE PROCEDURE: Patients underwent operative procedure under both local and general Anaesthesia. In powered endoscopy group, the Microdebrider (Unidrive II, Karl-Storz, Tutlingen, Germany) was used for surgical intervention. The entire procedure was carried out by the Microdebrider including polypectomy, middle meatal antrostomy, anterior and posterior ethmoidectomy, sphenoidotomy and frontal recess cleaning according to the extent of the disease. Cutting blades were used in the oscillating mode at 3,000 rpm. The extent of the surgical procedure was determined by CT findings, and the extent of mucosal disease and anatomic variations noted during surgery.

POSTOPERATIVE CARE: The nasal pack was removed the second day after surgery. Prophylactic antibiotic was given intravenously at the time of surgery and continued orally for 1 week. Saline nasal irrigation and topical steroid spray were used until healing of nasal mucosaoccurs. Patients were seen in the office for endoscopic debridement under local anaesthesia until mucosal healing was complete. The typical routine of postoperativevisits was days 1, 3, 10, 17 and 24 after surgery. Additional visits were needed in somepatients on weekly intervals till healing occurs, then routinely at 3- and 6-months intervals to evaluate the patient subjectively, objectively by endoscopic examination of the operatedcavities. The amounts of crusting, scarring and synechiae were documented at each visit.

\section{RESULTS}

Table 3: Associated Conditions Of Nasal Polyposis.

\begin{tabular}{|c|c|c|}
\hline Condition & No. of Patients & Percentage \\
\hline Allergic Rhinitis & 67 & 67 \\
\hline Chronic Sinusitis & 31 & 31 \\
\hline Asthma & 6 & 6 \\
\hline $\begin{array}{c}\text { Aspirin } \\
\text { Intolerance }\end{array}$ & 2 & 2 \\
\hline
\end{tabular}

Fig. 1: Symptomatology of Patients.

\section{SYMPTOMATOLOGY}

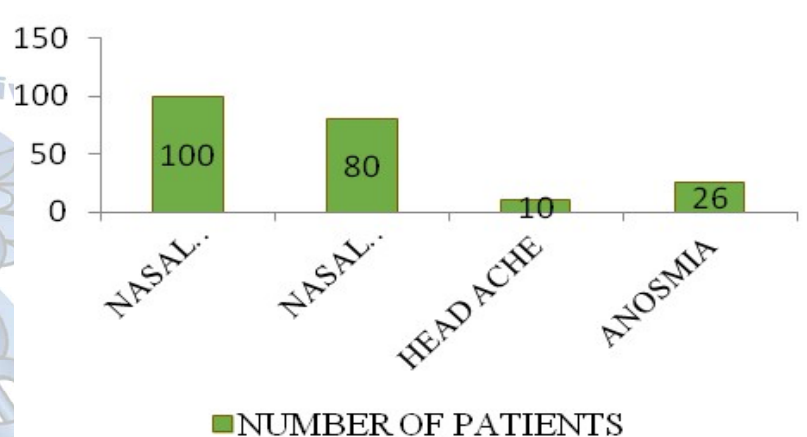

Most common symptom experienced was nasal obstruction (100\%), $80 \%$ of the patients had nasal discharge, $26 \%$ of the patients had anosmia and $10 \%$ of the patients had headache.

STAGE OF NASAL POLYPOSIS ON CLINICAL EXAMINATION: A large proportionof the study patients $(78 \%)$ were in stage 2 of disease. Stage 2 refers to polyp extending beyond the middle turbinate but not reaching the floor of the nasal passage, Stage $8 \%$ and stage $316 \%$.

LATERALITY OF POLYP: $72 \%$ of the study patients had unilateral involvement of nasal polyp, and $28 \%$ had bilateral involvement of nasal polyp.

Fig. 2: Laterality of Polyps.

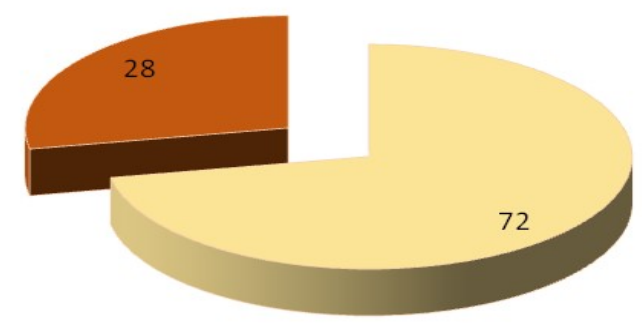

UNILATERAL $=$ BILATERAL 
Table 4: Endoscopic Grading Of The Polyps.

\begin{tabular}{|c|c|}
\hline Endoscopic Grading & Frequency \\
\hline Grade 0 & 23 \\
\hline Grade 1 & 48 \\
\hline Grade 2 & 21 \\
\hline Grade 3 & 8 \\
\hline Total & 100 \\
\hline
\end{tabular}

On endoscopic examination Grade 2 polyp (Polyp beyond middle meatus, not completely obstructing nose) was seen in 48 patients (48\%) and Grade3 (Polyp extending in to the floor of nasal passage) is seen in $8(8 \%)$ patients.

Table 5: CT Scan Grading Of Nasal Polyposis.

\begin{tabular}{|c|c|c|c|c|}
\hline Name Of The Sinus/Site & Grade 0 & Grade 1 & Grade 2 & Total \\
\hline Maxillary & $0 \%$ & $34 \%$ & $66 \%$ & 100 \\
\hline Anterior Ethmoid & $40 \%$ & $20 \%$ & $40 \%$ & 100 \\
\hline Posterior Ethmoid & $66 \%$ & $10 \%$ & $24 \%$ & $\mathbf{1 0 0}$ \\
\hline Sphenoid & $83 \%$ & $13 \%$ & $14 \%$ & $\mathbf{1 0 0}$ \\
\hline Frontal & $96 \%$ & $4 \%$ & $0 \%$ & 100 \\
\hline OMC & $8 \%$ & $33 \%$ & $59 \%$ & $\mathbf{1 0 0}$ \\
\hline
\end{tabular}

A large majority of patients with Maxillary sinus involvement had Grade2 $66 \%$ (totalopacification of sinus), Grade 0 (no involvement) and Grade 2 disease was seen in $40 \%$ of patients with anterior ethmoid sinus involvement, A large majority of the patients with Posterior ethmoid, Frontal and Sphenoidsinus involvement had Grade 0 disease.

Table 6: Mode of Treatment.

\begin{tabular}{|c|c|c|}
\hline Mode Of Treatment & $\begin{array}{c}\text { No. of } \\
\text { Patients }\end{array}$ & $\begin{array}{c}\text { No. } \\
\text { Improved }\end{array}$ \\
\hline Medical & 100 & 38 \\
\hline Surgery & 62 & 56 \\
\hline
\end{tabular}

All 100 patients were given intranasal steroids and short course of oral steroids. $38 \%$ showed improvement. Out of the 38 patients 26 had relief of nasal obstruction, 14 had decrease in the size of the polyp, and 9 had relief of anosmia. 62 patients underwent functional endoscopic sinus surgery, 56 had improvement and 6 patients had recurrence.

\section{DISCUSSION}

In the present study maximum study population were in the age group of 11 to 20 and 21 to 30 years who constituted $30 \%$ of population each, followed by 31 to 40 and 0 to 10 years who formed $16.7 \%$ and $13.3 \%$ respectively, $10 \%$ of population were in age group of $>40$ years. Out of the 100 patients 64 were males (64\%) and $36 \%$ were females (36\%). According to epidemiological analysis in patients with nasal polyps by Bettega $S$ etal, polyps are more common in elderly over the age group of 50 and rarely affects children and young people and men are more commonly affected with polyps (41.66\%) which is in accordance with this study [9]. In the present 67 patients had associated allergic rhinitis, 06 patients had asthma, 31 hadchronic sinusitis, and Only 2 patients of asthma had aspirin intolerance with nasal polyposis.Jovicevic Jet al. [10] showed the association of allergic rhinitis with nasal polyposis.Association between asthma and nasal polyps is commonly reported in literature asaround 7 to $20 \%$ with asthmatics over 40 years of age being more commonly affectedwith nasal polyps [11]. Nasal Polyposis affects from $5.2 \%$ to $13 \%$ of patients withasthma [12]. Staikûniene et al [13] in their study on Association of chronic rhinosinusitis with nasal polyps and asthma. clinical and radiological features, allergy and inflammation markers, showed that out of 121 patients with chronic sinusitis 84 patients $(69.4 \%)$ had nasal polyps.

In the present study nasal obstruction was the most common symptom that affected $100 \%$ of patients followed by voice change and mouth breathing being present in $83.3 \%$. Nasal discharge or anterior rhinorrhoea was reported by $80 \%$ of patients. $76.7 \%$ of patients suffered from anosmia and headache. Bettiga et al [9] in their epidemiological study found that the most frequent clinical manifestations were anterior and posterior rhinorrhoea and anosmia both were present in $90 \%$ of the patients, $80 \%$ of patients reported nasal obstruction; $60 \%$ reported sneezing; $50 \%$ reported itching and $30 \%$ of them reported conjunctivitis. According to Drake Lee et al the main presenting symptom of nasal polyp is nasal obstruction which is constant but can vary depending on the site and size of the polyps. Sufferers will also frequently complain of watery rhinorrhoea and postnasal drip. Anosmia or hyposmia with an ensuing alteration in taste are also characteristic symptoms of nasal polyp Radenne et al [14]. found that nasal polyps, besides causing nasal obstruction, hyposmia, and recurrent infection, impaired the 
quality of life more than perennial allergic rhinitis did [15].

Among 100 patients $78 \%$ were found to be having Stage II disease while 16 patients had Stage III disease.Lacroix et al in a histological comparison of nasal polyposis in black African, Chinese and Caucasian patients found that Stage I Nasal polyp was present in $22 \%$ of the Caucasians and $30 \%$ of the Chinese. Stage II was found in $58 \%$ of the Caucasians, $56 \%$ of the Chinese and $8 \%$ of the Africans. Stage III was found in $92 \%$ of the Africans, while only $20 \%$ of the Caucasians and $14 \%$ of the Chinese patients had stage III. The extent of submucosal oedema and number of mast cells were similar for the three groups of patients [16].

$72 \%$ of patients were found to be having unilateral disease and $28 \%$ of them were having bilateral disease on anterior rhinoscopic examination.Unilateral nasal polypwas common among children and adolescents and one third among them are antrochoanal polyp where infection plays a major role. Ethmoidal polyp arises from multiple ethmoidal air cells common among adults and elderly, mostly due to alleregy [17].

Among 100 patients 48 of them showed grade 2 stage of the polyps on nasalendoscopy. Followed by 23 who had grade 1 stage. Johansson Let al [18] compared thereproducibility of various score systems for staging nasal polyposis and the inter-individual variations between investigators.A score system with three steps ad modum Lund and Mackaydetermining their relationship to the middle meatus. Majority of the patients in the study had maxillary sinus involvement with total opacification of sinus of Lund Mackay Grade 2. CT provides objective information about inflammatory sinus disease. Yet evaluation of sinus disease using CT scan alone lacks sensitivity. Unfortunately, the fact remains that, though many staging systems have been proposed few have been tested. The number of currently published staging systems for sinusitis emphasizes the importance of developing a unified staging system, hence the recommendation by American academy of Otolaryngology, Head and neck surgery for adoption of modified Lund-Mackay system [19]. Ullah et al in their descriptive study on surgical management of massive nasal polyps observed on CT Scan, bilateral involvement of Ethmoids and Nasal cavities in $90 \%$ of cases, while orbital involvement was noted in $10 \%$ of cases and intracranial extension in 2 cases [20].

Out of 100 patients 38 patients showed improvement with intra nasal steroids and short course of systemic steroids. Most of the patients who showed improvement with steroids had grade 1 and grade 2 nasal polyps.62\% of patients underwent Functional endoscopic sinus surgery. 6 patients of them had recurrence. Tuncer $\mathrm{U}$ et al in their study out of 17 patients $12 \%$ had polpy free nasal cavity, $76 \%$ had clear involution of the polyp and $12 \%$ had no response [21]. Garrel Ret al in their study out of 132 patients who underwent endoscopic sinus surgery $62 \%$ had improvement [22]. Fokkens et al. showed in his study $5-10 \%$ of recurrence with severe disease [23].

\section{CONCLUSION}

Nasal polyps are one of the most common inflammatory mass lesions of the nose, they present with nasal obstruction, anosmia, rhinorrhoea, post nasal drip, and less commonly facial pain. In the present study Nasal polyps were found in large majority age groups of 11 30 years, men are most commonly seen affecting than women (men: women are 2:1).Allergic rhinitis is strongly associated with nasal polyposis, most common symptom is nasal obstruction, anosmia and facial pain are also seen.Most of the patients had nasal polyps reaching beyond the middle turbinate. And also, most of the patients had bilateral ethmoidalopacification on CT scan.only few showed sphenoid and frontal opacities.Steroid therapy was useful in 38\% of patients.All others required endoscopic sinus surgery. A better understanding of the pathophysiology underlying the persistent inflammatory state in nasal polyp is necessary to ultimately develop novelpharmacotherapeutic approaches.

\section{REFERENCES}

[1]. Mygind N, Lund J V, Jones R J. Nasal polyposis and Surgical management of rhinosinusitis. In: Gleeson M, Browning G G,Burton J M et al.Scott and Brown's Otorhinolaryngology, head and neck surgery, Edward Arnold publishers Ltd 2008, 7th edition, volume 2,pp: 1549-50,1552-56,1480-1. 
[2]. Davidson TM, Murphy C, Mitchell M, Smith C, Light M. Management of chronic sinusitis in cystic fibrosis. Laryngoscope. 1995;105:354-8.

[3]. Bachert C, Hörmann K, Mösges R, Rasp G, Riechelmann $H$, Müller R, et al. An update on thediagnosis and treatment of sinusitis and nasal polyposis. Allergy. 2003 Mar;58(3):176-91.

[4]. Nores JM, Avan P, Bonfils P. Medical management of nasal polyposis: a study in a series of 152 consecutive patients. Rhinology.2003;41:97-102.

[5]. Marks.S.C, Endoscopic sinus surgery. In: Marks S.C.Textbook on nasal and sinus surgery, W. B.Saunders Company 2000 pp: 119,125-26,140-141.

[6]. Becker SS. Surgical management of polyps in the treatment of nasal airway obstruction. Otolaryngol Clin North Am.2009;42:377-85.

[7]. Bruggers S, Sindwani R. Innovations in microdebrider technology and design. Otolaryngol Clin N Am. 2009;42:781-7.

[8]. Bernstein JM, Lebowitz RA, Jacobs JB. Initial report on postoperative healing after endoscopic sinus surgery with the microdebrider. Otolaryngol Head Neck Surg. 1998;118(6):800-3.

[9]. Bettega S, Soccol AT, Koerner HN, Mocellin M. Epidemiological Analysis in Patients with Nasal Polyps. Int. Arch. Otorhinolaryngol, 2007;11(3):243-9.

[10]. Jovicevic J, Kljajic V.Nasal polyposis and allergic rhinitis-our experience.Srp Arh Celok Lek. 2005;133:105-7.

[11]. Puwankar R. Nasal Polyposis: An Update. Curr Opin Allergy Immunol. 2003;3:1-6.

[12]. Slavin RG. Asthma and Sinusitis. J Allergy Clin Immunol. 1992; 90: 534-7.

[13]. Staikûniene J, Vaitkus S, Japertiene LM, Ryskiene S. Association of chronic rhinosinusitis with nasal polyps and asthma: clinical and radiological features, allergy and inflammation markers. Medicina (Kaunas). 2008;44(4):257-65.
[14]. Drake-Lee A. Nasal polyps. In: Kerr AG, editor. Scott Brown's otolaryngology. Oxford: Butterworth Heinemann; 1997;4:1-14.

[15]. Radenne F, Lamblin C, Vandezande LM, Tillie-Leblond I, Darras J, Tonnel AB, et al. Quality of life in nasal polyposis. J Allergy Clin Immunol. 1999;104(1):7984.

[16]. Lacroix JS, Zheng CG, Goytom SH, Landis B, Quinodoz $S$ MalisDD. Histological comparison of nasal polyposis in black African, Chinese and Caucasian patients. Rhinology.2002;40:118-21.

[17].M. Panduranga Kamath, Mahesh Chandra Hegde, Suja Sreedharan, K. Padmanabhan. Antrochoanal polyps and allergy-A comparative study. Indian J Otolaryngol Head Neck Surg. 2002 Jan; 54(1): 7-11.

[18].Johansson L, Akerlund A, Holmberg K, Melén I, Stierna P, Bende M. Evaluation of methods for endoscopic staging of nasal polyposis. Acta Otolaryngol. 2000;120:72-6.

[19].Joe AS, Bolger EM, Kennedy DW. Nasal endoscopy:Diagnosis and management In: Kennedy DW, Bolger EM, Zinreich J Diseases of Sinuses:Diagnosis and Management Pp:127.

[20]. Ullah N,Malik TL Pal MB. Surgical Management of Massive Nasal Polyps Special edition annals.2010;16.

[21]. Tuncer U, Soylu L, Aydogan B, Karakus F, Akcali C. The effectiveness of steroid treatment in nasal polyposis. Auris Nasus Larynx. 2003 Aug;30(3):263-8.

[22].Garrel R, Gardiner Q, Khudjadze M, Demoly $P$, Vergnes $C$, Makeieff $M$, et al. Endoscopic surgical treatment of sinonasal polyposis-medium term outcomes (mean follow-up of 5 years). Rhinology. 2003 Jun;41(2):91-6.

[23]. Fokkens W, Lund V, Mullol J. European Position Paper on Rhinosinusitis and Nasal Polyps Group. Rhinology. 2007; 45(2):97-101.

How to cite this article: R Sowmya, D Mahesh. A STUDY ON AETIOPATHOGENESIS AND MANAGEMENT OF NASAL POLYPOSIS. Int J Intg Med Sci 2019;6(5):839-844. DOI: 10.16965/ijims.2019.119 